\title{
Proses Komunikasi Dalam Pernikahan Etnis Madura
}

\author{
Nida Fitria Rahmadani, Ghina Farhany \\ Universitas Pembangunan Nasional Veteran Jakarta \\ e-mail: nidafitria45@gmail.com
}

\begin{abstract}
One of the ethnic groups in Indonesia who has special uniqueness in terms of their wedding customs is ethnic Madurese. In this study, research to supplement the consultation process of Madura marriage. This study uses qualitative methods by applying the sociocultural tradition. The technique of collecting data used is interview techniques and literature studies. The results of the study showed that the Madurese community still practiced matchmaking. Early marriage and security in the Madurese community begins with matchmaking and occurs due to certain factors such as increasing status and maintaining honor. Because second marriage begins with matchmaking, the communication process is related to the theory of social penetration, while communication between individuals moves to more intimate communication. In this case, non-verbal communication can be found in the wedding attire and tradition. This tradition includes pre-marriage, reception to post-marriage. In the communication process of Madurese ethnic, religious people has a significant role, from being the wedding planner to being the headman, depending on the tradition of the village.
\end{abstract}

Keywords: Madura Ethnicity, Communication Process, Customary Marriage

\begin{abstract}
Abstrak
Salah satu etnis di Indonesia yang memiliki keunikan tersendiri dalam hal adat pernikahannya ialah etnis Madura. Dalam penelitian ini, peneliti bertujuan untuk mempelajari lebih dalam mengenai proses komunikasi pernikahan etnis Madura. Penelitian ini menggunakan metode kualitatif dengan mengaplikasikan tradisi sosiokultural. Teknik pengumpulan data yang digunakan adalah teknik wawancara dan studi pustaka. Hasil penelitian menunjukkan bahwa masyarakat Madura masih melakukan praktik perjodohan. Pernikahan dini dan sataretanan di kalangan masyarakat Madura berawal dari perjodohan dan terjadi disebabkan keinginan untuk meningkatkan status kedudukan maupun menjaga kehormatan. Oleh karena kedua pernikahan tersebut berawal dari perjodohan, maka proses komunikasinya berkaitan dengan teori penetrasi sosial, di mana komunikasi antar individu bergerak ke komunikasi yang lebih intim. Komunikasi non-verbal dalam hal ini dapat ditemui dalam busana dan adat pernikahan. Adat pernikahan tersebut meliputi pra-nikah, resepsi hingga pasca pernikahan. Dalam proses pernikahan etnis Madura, pemuka agama memiliki peran yang sangat penting, yaitu mulai dari sebagai penata acara hingga sebagai penghulu, tergantung adat desa masingmasing.
\end{abstract}

Kata Kunci : Etnis Madura, Proses Komunikasi, Adat Pernikahan 

Latar Belakang Masalah

Indonesia terdiri dari lebih 300

kelompok etnik atau suku bangsa di

Indonesia, atau tepatnya 1.340 suku

bangsa menurut sensus BPS tahun

2010. Madura merupakan salah satu

bagian dari kelompok etnik atau suku

bangsa tersebut.

Etnis Madura berasal dari

Pulau Madura yang terletak di Jawa

Timur. Menurut sensus tahun 2010,

populasi etnis Madura sangat besar

yaitu berjumlah sekitar 7.179 .356

jiwa yang tersebar diberbagai daerah

di Indonesia.

Kesenian dan kebudayaan yang

dimikiki etnis Madura sangat

banyak, diantaranya rumah adat

Madura, senjata tradisional Madura,

pakaian adat Madura, musik

Saronen, Karapan Sapi, Upacara

Sandhur Pantel, tarian-tarian adat

Madura seperti tarian Rampak Jidor,

tarian Topeng Gethak dan Tarian
Rondhing.

Tak hanya kesenian dan kebudayaan saja, Madura juga memiliki tradisi dan adat yang unik, termasuk tradisi atau adat perkawinan.

Jalaludi Tunsam (dalam Div Natha, 2017: 1) menyatakan bahwa adat berasal dari bahasa arab yang meupakan bentuk jamak dari 'adah' berarti cara atau kebiasaan. Secara istilah, adat merupakan suatu gagasan kebudayaan yang mengandung nilai kebudayaan, norma, kebiasaan serta hukum yang sudah lazim dilakukan oleh suatu daerah.

Sedangkan Tradisi menurut KBBI adalah kebiasaan turuntemurun (dari nenek moyang) yang masih dijalankan dalam masyarakat. WJS Poerwadaminto

menyatakan bahwa tradisi merupakan segala sesuatu yanng 
menyangkut kehidupan dalam

masyarakat yang dilakukan secara

terus menerus, seperti kebudayaan

atau kebiasaan.

Menurut UU perkawinan NO.1

Tahun 1974, “perkawinan adalah

ikatan lahir batin antara seorang pria

dengan seorang wanita sebagai

suami istri dengan tujuan

membentuk rumah tangga yang

bahagia lahir maupun batin dan kekal

berdasarkan ketuhanan Yang Maha

Esa". Sedangkan menurut Maya

(2013), “pernikahan adalah adanya

suatu bentuk pola sosial yang

disetujui oleh kedua belah pihak

(pria dan wanita) yang sehingga

mampu membentuk keluarga yang

sah dimana agama dan legal dimata

hukum”.

Jadi, adat atau tradisi

perkawinan adalah suatu kebudayaan

atau kebiasaan dalam pernikahan

yang dilakukan oleh masyarakat di daerah.

Untuk mengetahui lebih dalam lagi mengenai apa saja bentukbentuk tradisi pernikahan etnis Madura, bagaimana proses komunikasi yang terjadi dalam tradisi pernikahan Madura (Pernikahan Dini dan Sataretanan), makna komunikasi nonverbal dalam busana pernikahan dan proses pernikahan etnis Madura, serta peran pemuka agama dalam proses pernikahan Madura, maka dilakukanlah penelitian ini.

Dalam kajian ini, digunakan tradisi sosiokultural. Tradisi sosiokultural terhadap teori komunikasi menunjukkan cara pemahaman kita terhadap makna, norma, peran, serta peraturan yang dijalankan secara interaktif dalam komunikasi.

Teori

sosiokultural

memfokuskan diri pada bentuk- 
bentuk interaksi manusia daripada karakteristik individu.

\section{Metode Penelitian}

Jenis penelitian yang

digunakan adalah penelitian

kualitatif. Menurut Lexy J. Meleong

(2005:6), metode penelitian kualitatif

adalah suatu riset yang bermaksud

untuk memahami fenomena yang

dialami oleh subjek penelitian,

misalnya perilaku, persepsi,

tindakan, dan lain-lain secara

holistic, dengan deskripsi dalam

bentuk kata-kata dan bahasa, pada

suatu konteks khusus alamiah dan

dengan memanfaatkan berbagai

metode alamiah.

Rachmat Kriyanto menyatakan

bahwa penelitian kualiatatif

bertujuan untuk menjelaskan

fenomena yang terjadi dimasyarakat

secara

mendalam

dengan

mengumpulkan data secara mendalam dan lengkap.

Data yang dikumpulkan

meliputi data primer dan data

sekunder. Data primer dikumpulkan

dengan teknik wawancara dengan

beberapa narasumber. Sedangkan

data sekunder dikumpulkan melalui

studi pustaka yang bersumber dari

jurnal ilmiah dan buku.

Analisis data dilakukan sejak awal data dikumpulkan melalui wawancara dengan narasumber.

Hasil wawancara ditulis dalam bentuk catatan dan kemudian dianalisis sebelum disusun agar lebih teratur.

Pendekatan yang digunakan dalam penelitian ini adalah deskriptif. Pendek atan ini digunakan untuk membuat penjelasan secara akurat dan faktual yang sesuai dengan fakta-fakta yang telah ditemukan. 
Hasil Penelitian dan Pembahasan

a. Bentuk-Bentuk

Tradisi

\section{Pernikahan Etnis Madura}

Sebenarnya, tradisi pernikahan

di Madura sangat beraneka ragam

dan tergantung pada daerahnya, karena setiap daerah memiliki tradisi yang berbeda-beda.

Dalam penelitian ini tidak akan membahas semua tradisi pernikahan etnis Madura, namun peneliti akan membahas tradisi pernikahan yang biasanya memang ada di setiap daerah di Madura.

\section{Pernikahan Dini}

Menurut salah satu narasumber kami, alasan pernikahan dini dilakukan oleh orang Madura adalah untuk menjaga kehormatan perempuan dan meningkatkan status laki-laki dengan ikatan pernikahan. Orang-orang Madura beranggapan bahwa jika mereka tidak segera menikahkan anak mereka, maka akan timbul banyak fitnah. Oleh karena itu, pernikahan dini di Madura biasanya dilakukan atas dasar perjodohan.

$$
\text { Pernikahan dini yang }
$$
dilakukan oleh masyarakat Madura juga tidak sembarang dilakukan. Oleh karena itu, biasanya mereka terlebih dahulu melihat garis keturunan si calon pasangan.

Narasumber kami juga mengatakan bahwa dalam pernikahan diri etnis Madura, hanya wanita yang berusia dini. Sedangkan untuk pria, tidak ada batasan usia.

Dampak yang ditimbulkan dari pernikahan dini sangat beragam. Narasumber kami, yaitu Rifa Mukti yang berasal dari Sumenep, mengatakan bahwa selain menimbulkan dampak traumatis bagi pihak perempuan, tingkat kebahagiaan dari pernikahan dini juga sangat rendah. Oleh karena itu, 
menurutnya banyak yang berakhir

dengan perceraian. Namun tak

sedikit pula, yang pernikahannya

sangat langgeng sampai tua.

2. Pernikahan Sataretanan

Sesuai dengan sebutannya, pernikahan sataretanan merupakan pernikahan antar saudara. Artinya, baik dari pihak laki-laki dan perempuan masih memiliki ikatan kekeluargaan atau persaudaraan.

Namun menurut narasumber kami, saat ini pernikahan sataretanan juga bisa dianggap pernikahan antar kerabat dekat yang bukan saudara dekat. Pernikahan ini juga mayoritas atas dasar perjodohan.

b. Proses Komunikasi dalam Pernikhan Dini dan

\section{Pernikahan Sataretanan}

Komunikasi adalah proses penyampaian pesan dari pengirim ke penerima, baik itu pesan verbal maupun pesan non verbal. Menurut
Joseph A. Devito, dalam bukunya yang berjudul Komunikasi Antarmanusia Edisi Kelima, komunikasi mengacu pada tindakan, oleh satu orang atau lebih, yang mengirim dan menerima pesan yang terdistorsi oleh gangguan (noise), yang terjadi dalam suatu konteks tertentu, mempunyai pengaruh tertentu, dan ada kesempatan untuk melakukan umpan balik.

Laswell mengatakan bahwa proses komunikasi dimulai dari pengirim pesan (sender) yang menyampaikan pesan (message) melalui media (medium) yang diterima oleh penerima pesan (receiver) yang kemudian menciptakan umpan balik (feedback) yang diberikan penerima pesan kepada pengirim pesan.

Berdasarkan hasil wawancara, pernikahan dini dan pernikahan sataretanan mayoritas dilakukan atas 
dasar perjodohan. Karena atas dasar

perjodohan tersebut, kedua calon

pasangan tersebut biasanya belum

saling mengenal secara mendalam

pada saat belum menikah. Lalu pada

saat setelah menikah, barulah mereka

melakukan proses pengenalan lebih

dalam antar kedua belah pihak.

Jika hal itu dilihat dari perspektif teori, maka proses komunikasi yang terjadi dalam pernikahan dini dan pernikahan sataretanan sesuai atau berkaitan dengan teori penetrasi sosial.

Teori penetrasi sosial adalah teori yang menggambarkan suatu pola hubungan, dimana komunikasi antar individu bergerak ke komunikasi yang lebih intim.

Altman dan taylor menyatakan bahwa dalam teori penetrasi sosial, ada empat tahap pengembangan hubungan. Tahap pertama yaitu orientasi, dalam tahap ini seseorang hanya mengungkapkan informasi yang sangat umum. Tahap kedua yaitu pertukaran afektif eksploratif, merupakan gerakan yang menuju sebuah tingkat yang lebih dalam dari pengungkapan yang terjadi. Tahap ketiga yaitu pertukaran afektif, terpusat pada perasaan mengkritik dan mengevaluasi pada tingkat yang lebih dalam. Dan tahap terakhir yaitu pertukaran yang seimbang, merupakan kedekatan yang tinggi dan memungkinkan mereka untuk saling memperkirakan tindakan dan respons dengan baik.

Joseph A. Devito dalam bukunya yang berjudul Komunikasi Antarmanusia Edisi Kelima, mengatakan bahwa teori penetrasi sosial dengan berkembangnya hubungan dalam teori penetrasi sosial, maka keluasan dan kedalaman semakin meningkat. 
c. Makna Komunikasi

Nonverbal dalam Busana

\section{Pernikahan Etnis Madura}

Komunikasi nonverbal adalah

jenis penyampaian pesan tanpa menggunakan kata-kata. Biasanya

media yang digunakan seperti isyarat ataupun simbol-simbol.

Jenis-jenis Komunikasi

nonverbal sangat banyak, salah satunya ada artefak atau psycal appearance, yaitu cara menampilkan diri melalui penggunaan bendabenda atau penampilan fisik yang dapat menyampaikan pesan tertentu. Misalnya busana, aksesoris, dan lainlain.

Busana atau pakaian memiliki peran yang penting. Apalagi saat seseorang bertemu untuk pertama kalinya dengan orang lain, pakaian dapat menyampaikan informasi mengenai orang tersebut.

Begitupun melangsungkan pernikahan, busana yang dikenakan oleh Pengantin dapat memiliki arti atau melambangkan hal tertentu.

Menurut narasumber kami, yaitu Faang yang berasal dari Kabupaten Bangkalan, busana pengantin asal Madura memiliki arti yang sangat mendalam. Pakaian komprang untuk pria melambangkan keberanian dan tanggung jawab pria Madura. Artinya, pria berani mengambil keputusan untuk menikahi si wanita dan bertanggung jawab sepenuhnya setelah menikah nanti.

$$
\text { Sedangkan }
$$

wanita menggunakan pakaian trawang, yang memiliki arti bahwa setelah menikah, wanita akan patuh dan setia kepada suaminya.

$$
\text { Sebenarnya }
$$
pakaian pernikahan khas etnis Madura tak hanya komprang dan trawang saja, 
namun banyak jenisnya sesuai

dengan daerahnya masing-masing.

Bahkan pada jaman dahulu, pakaian pernikahan diklasifikasikan sesuai dengan status sosialnya, jadi pakain pernikahan untuk rakyat biasa dan bangsawan berbeda.

Faang juga mengatakan bahwa untuk saat ini, pakaian adat pernikahan etnis Madura sudah jarang dipakai oleh pengantin pada umumya. Karena sekarang pakaian pengantim sudah ikut modernisasi.

\section{d. Komunikasi Nonverbal dalam \\ Proses Pernikahan Etnis}

\section{Madura}

Berdasarkan hasil wawancara dengan Faang, berikut adalah proses pernikahan etnis Madura berserta maknanya.

\section{- $\quad$ Adat Pra Nikah}

Sebelum menikah, sang calon pengantin pria akan datang terlebih dahulu ke Rumah sang wanita.
Kedatangan tersebut bermaksud untuk melamar si wanita, dengan membawa cincin dan seperangkat pakaian untuk sang wanita, serta juga ada aneka jajanan dan makanan. Di Madura, acara ini dikenal dengan sebutan 'bekalan' atau 'tunangan'.

- Resepsi Pernikahan

Biasanya akad nikah dan resepsi pernikahan etnis Madura dilaksanakan terpisah atau berbeda hari, namun itu tergantung adat desanya. Misal, akad di bulan Rajab, resepsinya dilaksanakan pada bulan Syawal (Tong Areh). Masyarakat Madura umumnya tidak mengadakan resepsi di bulan Dzulqoidah atau dalam bahasa Madura disebut tekepek.

Berikut rangkaian acara dalam resepsi pernikahan etnis Madura:

$>$ Lek Melek, dilakukan pada malam hari sebelum acara resepsi diadakan. 


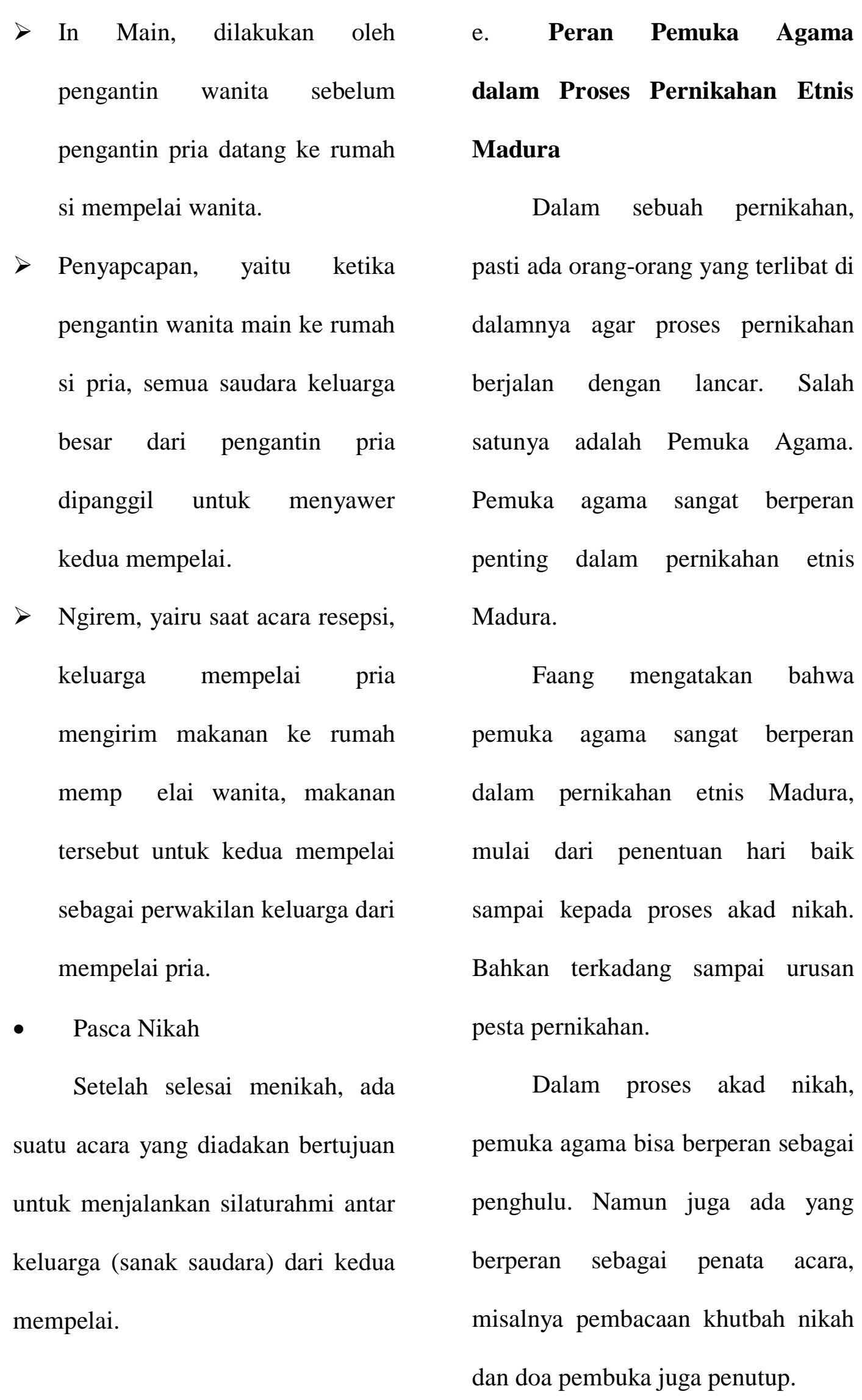


Namun tak semua pemuka agama berperan seperti itu, tergantung adat desa masing-masing.

\section{Penutup}

Komunikasi merupakan suatu hal penting yang membantu kita dalam menjalani kehidupan. Semua kegiatan sehari-hari pasti membutuhkan komunkasi, termasuk dalam melakukan pernikahan. Dalam pernikahan, dibutuhkan proses komunikasi untuk membantu lakilaki dan perempuan agar lebih mengenal satu sama lain secara mendalam.

Berdasarkan hasil penelitian, dapat disimpulkan bahwa masyarakat Madura masih melakukan praktik perjodohan. Pernikahan dini dan sataretanan di kalangan masyarakat Madura berawal dari perjodohan dan terjadi disebabkan keinginan untuk meningkatkan status kedudukan maupun menjaga kehormatan. Oleh karena kedua pernikahan tersebut berawal dari perjodohan, maka proses komunikasinya berkaitan dengan teori penetrasi sosial, di mana komunikasi antar individu bergerak ke komunikasi yang lebih intim. Komunikasi non-verbal dalam hal ini dapat ditemui dalam busana dan adat pernikahan. Adat pernikahan tersebut meliputi pranikah, resepsi hingga pasca pernikahan. Dalam proses pernikahan etnis Madura, pemuka agama memiliki peran yang sangat penting, yaitu mulai dari sebagai penata acara hingga sebagai penghulu, tergantung adat desa masing-masing.

\section{Daftar Pustaka}

Devito, Joseph A.. 2011 Komunikasi Antara usia Edisi Kelima. Tanggerang: Karisma Publishing Group. 
Iswara, Tiara Widya., dan Irine Firsta Herlia. 2016. Tradisi Pernikahan Budaya Madura sebagai Komodifikasi untuk Menunjukkan Status Sosial Dalam Masyarakat (Studi Kasus di Pulau Giliyang, Sumenep). Jurnal disajikan dalam Seminar Nasional Gender \& Budaya Madura III Madura: Perempuan, Budaya \& Perubahan, Universitas Trunojoyo Madura, Jawa Timur.

Littlejohn, W. Stephen., dan Karen A. Foss. 2017. Teori Komunikasi Edisi 9. Jakarta: Salemba Humanika.

Wijaya, Div Natha. 2017. "Pengertian Adat Secara Umum Dan Menurut Bebrapa Sumber". $15 \quad$ Maret 2017. (https://www.scribd.com/docum ent/341941509/Pengertian-AdatSecara-Umum-Dan-MenurutBebrapa-Sumber), diakses pada 26 Mei 2019.

Setiawan, Samhis. 2019. "Adat Istiadat: Pengertian, Jenis, Kriteria, Dan Contohnya". 05 Januari 2019. (https://www.gurupendidikan.co. id/adat-istiadat-dan-contohnya/), diakses pada 26 Mei 2019.

Sudahri. 2013. Tradisi Komunikasi dalam Pernikahan Adat Madura Desa Sanahdaya Kecamatan Pasean Kabupaten Pamekasan. Jurnal Politico. (Online), jilid XII, No.2, (http://digilib.unmuhjember.ac.i d/files/disk1/31/umj-1x-sudahri1540-1-7.sudah-3.pdf, diakses 25 Mei 2019). 